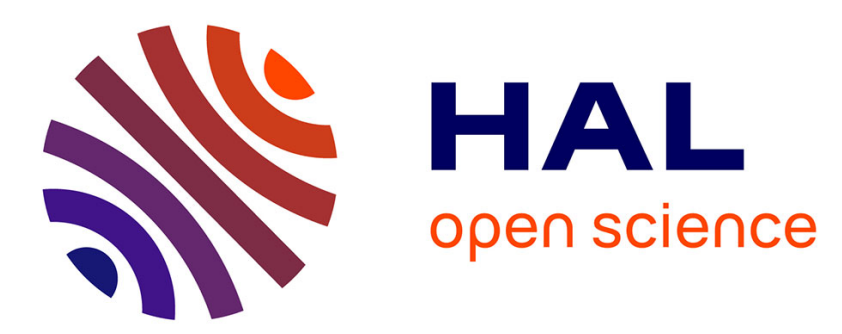

\title{
Design of a protection thermal energy storage using phase change material coupled to a solar receiver
}

David Verdier-Gorcias, Quentin Falcoz, Alain Ferriere

\section{To cite this version:}

David Verdier-Gorcias, Quentin Falcoz, Alain Ferriere. Design of a protection thermal energy storage using phase change material coupled to a solar receiver. High-temperature materials and processes, 2014. hal-03368383

\section{HAL Id: hal-03368383 https://hal.science/hal-03368383}

Submitted on 6 Oct 2021

HAL is a multi-disciplinary open access archive for the deposit and dissemination of scientific research documents, whether they are published or not. The documents may come from teaching and research institutions in France or abroad, or from public or private research centers.
L'archive ouverte pluridisciplinaire HAL, est destinée au dépôt et à la diffusion de documents scientifiques de niveau recherche, publiés ou non, émanant des établissements d'enseignement et de recherche français ou étrangers, des laboratoires publics ou privés. 
D. Verdier, Q. Falcoz* and A. Ferrière

\section{Design of a Protection Thermal Energy Storage Using Phase Change Material Coupled to a Solar Receiver}

\begin{abstract}
Thermal Energy Storage (TES) is the key for a stable electricity production in future Concentrated Solar Power (CSP) plants. This work presents a study on the thermal protection of the central receiver of CSP plant using a tower which is subject to considerable thermal stresses in case of cloudy events. The very high temperatures, $800{ }^{\circ} \mathrm{C}$ at design point, impose the use of special materials which are able to resist at high temperature and high mechanical constraints and high level of concentrated solar flux. In this paper we investigate a TES coupling a metallic matrix drilled with tubes of Phase Change Material (PCM) in order to store a large amount of thermal energy and release it in a short time. A numerical model is developed to optimize the arrangement of tubes into the TES. Then a methodology is given, based from the need in terms of thermal capacity, in order to help the choice of the geometry.
\end{abstract}

Keywords: phase change material (PCM), solar energy, solar receiver, thermal energy storage (TES), concentrated solar power (CSP), high temperature (HT)

PACS $^{\circledR}$ (2010). 44.35.+c, 88.40.-j

*Corresponding author: Q. Falcoz: PROMES CNRS UPR 8521, Perpignan University, 66120 Font-Romeu-Odeillo-Via, France. E-mail: Quentin.falcoz@promes.cnrs.fr

D. Verdier, A. Ferrière: PROMES CNRS UPR 8521, Perpignan University, 66120 Font-Romeu-Odeillo-Via, France

\section{Introduction}

\subsection{TES devices for CSP plants}

This paper is dedicated to Thermal Energy Storage (TES) for Concentrated Solar Power (CSP) plants using a tower and a Central Receiver System (CRS). Indeed while the solar source is free and infinite, it is also intermittent and variable in particular because of the night and day cycle. Production of electricity requires the turbine to be closest to its nominal mode. Energy storage makes it possible to smooth the electrical production and is so inevitable to produce electricity with a high added-value. This production storage also gives the possibility to adapt energy supply with energy demand. Referring to Calvet [1], two kinds of production storages are distinguished, active and passive storages: active ones are characterized by an imposed convection in the storage material and often needs large amount of materials. Main examples are: Direct Steam Generation (DSG) in PS10 Abengoa ${ }^{\circledR}$, Spain; molten solar salt in Solar Two Andasol, Spain; solar oil in Solar Energy Generating Systems (SEGS) plant, California, USA; passive storages need a thermal exchanger between the Heat Transfer Fluid (HTF) and the storage material (often solid). This exchanger causes a decrease of the yield. As example of passive storages, the DLR Laboratory, Germany, has developed sand storage concept, ceramics and high temperature concrete.

Another kind of storage is the protection storage. Contrary to the production storage, its aim is to protect the different elements of the solar plant, in particular the solar receiver, first element impacted by the concentrated solar flux. To protect the solar receiver against important variations of temperature (causes by a cloudy passage), a powerful storage is needed, i.e. which can deliver the totality of its energy in less than a quarter, in a range of temperatures between 600 and $800{ }^{\circ} \mathrm{C}$. In this paper we propose a solution for thermal protection storage for the CSP tower plant of Thémis (Targassonne, France) into the Pegase project (Production of Electricity from Gas and Solar Energy). The architecture of the plant imposes to design storage with a large density because it will be installed at the back of the receiver at the top of the tower. This is the reason why the geometry of the storage has to integrate Phase Change Material (PCM) which is known for the high capacity of thermal storage.

As such, a study of Farid [2] has listed the main applications of PCMs for solar energy (heating or cooling systems), building applications, and electricity production. Among the whole of phase change materials used in these domains we find hydrated salts, paraffin wax, fatty acids and eutectics of organic and non-organic 
compounds. An inventory of more than 150 PCMs has been made by Zabla [3] over the last 20 years. In Zabla's list of PCMs, inorganic substances are retained, only materials supporting very high temperatures. Unfortunately, inorganic materials may also present undercooling, corrosion, and a low thermal stability. More, the use of PCMs is not appropriate with the discharge power required for the unit. Indeed, PCMs have thermal conductivities very low. This is the reason why we investigate in this article how to enhance the thermal conductivity.

\subsection{Thermal conductivity enhancement for TES using PCMs}

Conscious of the problem concerning the low thermal conductivity of PCMs, many researchers have developed methods to enhance it. At microscopic scale with addition of graphite particles, or at macroscopic scale using nodules or particular metallic geometries.

\subsubsection{Graphite at microscopic scale for thermal conductivity enhancement}

Several methodologies have been reported in the literature based on the theoretical and experimental investigations to enhance the heat transfer by using fins of various configurations as Shatikian [4] for example, or by saturating porous metals with PCM, and impregnating a porous graphite matrix with PCM [5-6].

A solution has been proposed by Pincemin et al. [7] for solar processes under medium concentration, in the range of $200-300{ }^{\circ} \mathrm{C}$. They have intensified the thermal conductivity of the TES by adding of graphite at microscopic scale in order to change intrinsic properties of the material. In conclusion, the performances of latent heatbased TES have been significantly intensified using new composite materials made of inorganic PCMs and graphite. Thus the thermal conductivity has been multiplied by a factor 14 up to $9 \mathrm{~W} / \mathrm{m} \cdot \mathrm{K}$. However they have remarked that the thermal conductivity decreases quickly with the temperature growth, $-2.25 \% /{ }^{\circ} \mathrm{C}$. The authors have also explained that, according to their simulation approach, each particular case of application would lead to a specific technico-economic optimum defined by the graphite amount within the composite and the interfoil distance between the graphite particles.

\subsubsection{Thermal conductivity enhancement at macroscopic scale}

At macroscopic scale, a review made by Alkilani [8] has listed various methods to intensify storage energy in building applications like the TES using water as HTF and solar panels. Saman et al. [9] have analyzed the thermal performances of a phase change storage unit as a component of a roof integrated solar heating system. The unit consists of several layers of PCM slabs with melting temperature of $29^{\circ} \mathrm{C}$. Warm air, delivered by a roof irradiated by the Sun, passes through the spaces between the PCM layers to charge the storage unit. Then in absence of Sun, the unit discharges its heat and keeps the air warm.

Researchers have also used encapsulation techniques to enhance heat transfer as Zhang et al. [10] with a microencapsulated PCM based on an n-octadecane core and an inorganic silica shell. Indeed encapsulation intensifies the heat transfer by increasing the exchange surface between the HTF and the PCM. For example, at temperatures lower than $100{ }^{\circ} \mathrm{C}$, Zukowski [11] has used paraffin wax encapsulated to improve performances of air treatment in building applications. In the same way, Onder [12] has used microcapsules of paraffin wax to improve performances of textiles materials by a coefficient of between 2.5 and 4.5 compared to standards, still at low temperatures.

Another method is the integration of PCM into a macroscopic metallic matrix. Hasse [13] has proposed, for example, the use of a honeycomb wallboard because this configuration allows a large surface area in contact with the PCM (exchange surface). Experiments lead by Hasse has used aluminum as a metallic matrix and paraffin wax as PCM in the range of temperatures $11-39^{\circ} \mathrm{C}, 24 \mathrm{~h}$ period. The results have shown the efficiency of latent heat storage and the experimental curves have been well represented by numerical simulations.

\subsection{Phase change modeling}

Modeling is a useful tool regarding the analysis of a TES containing liquid-solid PCM and in the designing of its prototype. In the review of Zabla et al. [3], one of the sections deals with the latent heat transfer problem under four different approaches: moving boundary problems, numerical solution considering only conduction, numerical solution considering only convection, and numerical simulation in different heat exchanger geometries. The authors have remarked that although there is a huge amount of published articles dealing with the heat transfer analysis of PCM, the modeling of latent heat TES still 
remains a challenging task. In fact, one of the main problems, highlighted by Hed et al. [14], concerned the use of a commercial PCM. In their development of a mathematical model of a PCM-air heat exchanger, the authors have noticed the importance of the thermo-physical properties of the PCM as there is a completely different behavior between an ideal PCM and its commercial homologue. For example, the shape of heat capacity curve affects specifically the heat transfer. Thus, the phase change takes place over a temperature range and therefore a two phase zone, the mushy region, appears between the solid and the liquid phases. Hence, according to Dolado's model [15], it is appropriate to consider the energy equation (Eq. (1)), in terms of enthalpy (Eq. (2)). The advantage of this method is that the equation is applicable to every region.

$$
\begin{gathered}
\rho C_{p} \frac{\partial T}{\partial t}=\lambda \Delta(T) \quad\left(W / m^{3}\right) \\
\frac{\partial h}{\partial t}=\lambda \Delta(T) \quad\left(W / m^{3}\right)
\end{gathered}
$$

where $\mathrm{T}$ defined the temperature (K), $\mathrm{h}$ is the enthalpy per volume unit of the PCM $\left(\mathrm{J} / \mathrm{m}^{3}\right), \rho, \mathrm{Cp}, \lambda$ (S.I.) are the density, the heat capacity, and the thermal conductivity of the PCM.

Then, researchers like Bhattacharya [16] have considered an effective thermal conductivity for the PCM, sort of a mean between the solid value and the liquid value. The author has used a parameter " $\mathrm{f}_{1}$ ", the fraction of liquid in the PCM, as a function of the temperature to weight the value of the efficient conductivity between the solid and the liquid value. This parameter $\mathrm{f}_{1}$ goes from 0 (all the PCM is solid) to 1 when all the PCM becomes liquid. In the heat equation (Eq. (1)), the thermal conductivity $\lambda$ so can be replaced by:

$$
\begin{gathered}
\lambda_{\text {eff }}=\lambda_{\text {solid }} \times\left(1-f_{l}\right)+\lambda_{\text {liquid }} \times f_{l} \quad(W / m . K) \\
f_{l}=\left\{\begin{array}{cll}
0 & T<T_{m} & \text { solid } \\
0,1[ & T=T_{m} & \text { mushy } \\
1 & T>T_{m} & \text { liquid }
\end{array}\right.
\end{gathered}
$$

The model of the PCM with enthalpy balance has to take into account the production/absorption of energy during the phase change. This energy can be modeled with an addition of a source term $\mathrm{P}$ (positive for heat production, solidification, and negative for heat absorption, melting) in the heat equation. According to Dutil [17], for a phase change process, energy conservation can be expressed in terms of total volumetric enthalpy and temperature for constant thermo-physical properties as follows:

$$
h(T)=\int_{T_{m}}^{T}(\rho C p(T) d T)+P \quad\left(J / m^{3}\right)
$$

Thereafter, the term $\mathrm{P}$ is associated to the latent heat of the PCM as a function of the fraction of matter that becomes liquid during his phase change.

$$
P=+\rho L f_{l} \quad\left(J / m^{3}\right)
$$

where $\mathrm{L}$ is the latent heat $(\mathrm{J} / \mathrm{kg})$ of the PCM.

From the heat equation (Eq. (1)) and according to Farid studies [2], it is also possible to consider the PCM has a material with a unique phase and a unique heat capacity named "equivalent" and subscripted as $\mathrm{Cp}_{\mathrm{e}}$ :

$$
C p_{e}=C p+L \frac{\partial f_{l}}{\partial T} \quad(J / k g \cdot K)
$$

In general, the shape of the $\mathrm{Cp}_{\mathrm{e}}$ curve is determined from experimental studies. Then the shape is modeled in a way that the area under the curve equals the latent heat of the material.

\section{Materials and methods}

\subsection{Description of the solar receiver and the associated TES}

The TES developed in this study is dedicated to a very innovative type of CSP plant, i.e. Hybrid Solar Gas Turbine (HSGT) power station. In the HSGT concept, air is used as HTF and is heated at very high temperature trough a solar receiver placed at the top of a tower. Through the Pegase project (ADEME, CNRS, EDF), previous researches, lead by Grange et al. [18], have focused on the development of a metallic surface receiver able to reach an outlet air temperature of $750{ }^{\circ} \mathrm{C}$ at a flow rate of $8 \mathrm{~kg} / \mathrm{s}$. The receiver, which is basically a heat exchanger between the concentrated solar flux and the air flow, is the first element impacted by variations of temperature due to irradiation variations (when a cloud temporally hides the Sun for example). These temperature variations imply important mechanical constraints on the surface receiver and cause a premature ageing of materials. In this context, it appears relevant to add some thermal inertia to the solar receiver by placing a TES module on the back of a solar receiver (see Fig. 1). 


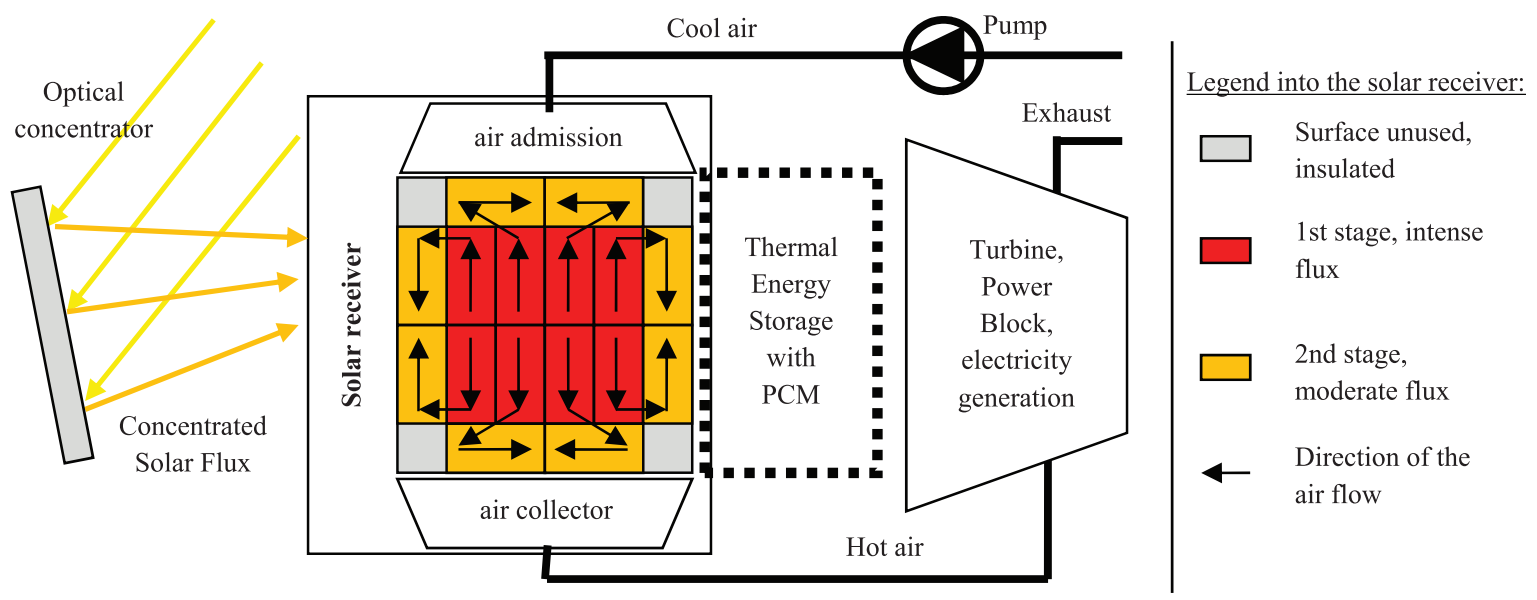

Fig. 1: Drawing of the TES coupled to the Pegase solar receiver and solar plant synopsis with pressurized air flow [18]

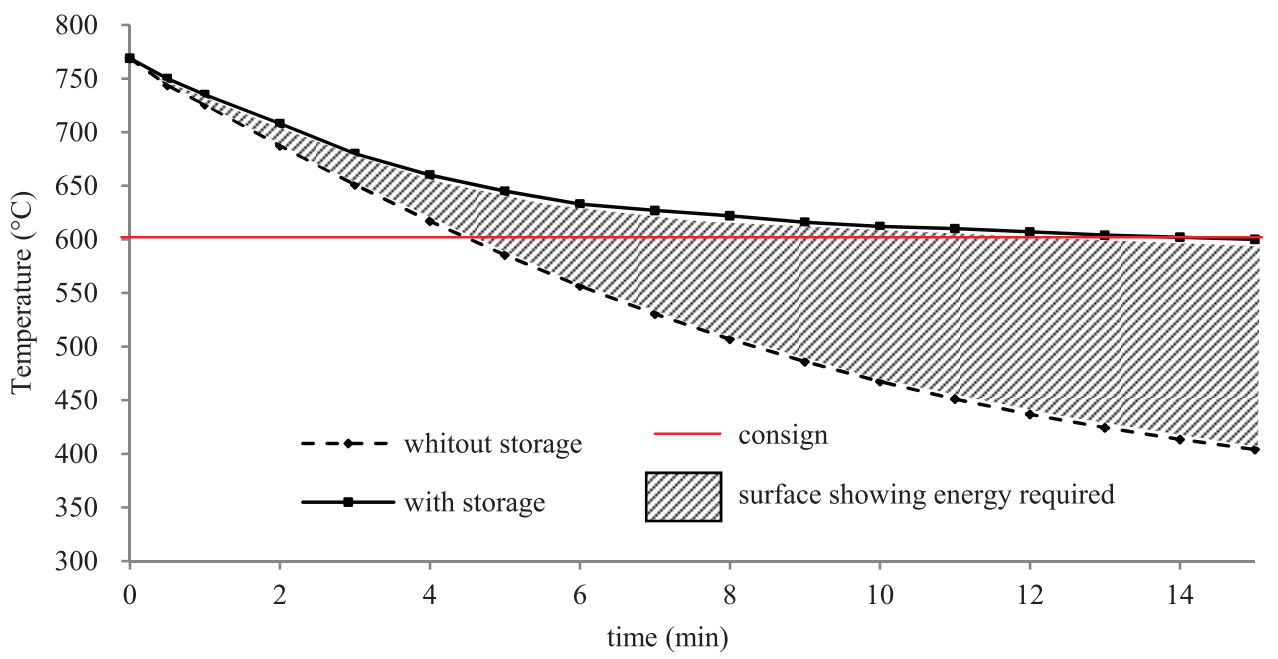

Fig. 2: Target evolution of the receiver outlet air temperature in absence of solar flux (Drawn from Grange thesis estimations)

For the moment, the Pegase project consists in a demonstrator receiver of 1.2 meter square $\left(1.44 \mathrm{~m}^{2}\right)$, modular and multi-staged (i.e. there are two stages of eight modules for two levels of flux), heating air from $350^{\circ} \mathrm{C}$ to $750{ }^{\circ} \mathrm{C}$. Each module is a $20 \mathrm{~cm}$ wide and $40 \mathrm{~cm}$ long copper/inconel metallic matrix drilled with 45 tubes in which air flows.

Grange et al. [18] have demonstrated with a numerical approach that if we cut the solar irradiation, the outlet air temperature (without TES module) decreases to $400{ }^{\circ} \mathrm{C}$ in less than 15 minutes (dotted line in Fig. 2). Hence, in order to improve the thermal inertia and the life of the solar receiver, we decide to impose a specification to the TES module. The protection storage module must be designed in order to achieve this constraint: the outlet air temperature must be up to $600{ }^{\circ} \mathrm{C}$ after 15 minutes without any solar contribution (red line and solid black line in Fig. 2). The temperature of $600{ }^{\circ} \mathrm{C}$ has been chosen because it corresponds to the lower limit of the nominal operation temperature range of the gas turbine.

So the operation range temperature of the TES module will be between $600{ }^{\circ} \mathrm{C}$ (the target temperature for the outlet air) and $800{ }^{\circ} \mathrm{C}$ (the receiver surface temperature in operation).

\subsection{Choice of the couple PCM/metal}

Thus the phase change material (PCM) has to change in this range of temperatures. According to the list of Zabla et al. [3], paraffin, fatty acids and organic PCMs are not considered because their phase change temperatures are lower than $150{ }^{\circ} \mathrm{C}$. According to Kenisarin [19], the basic requirements imposed upon phase change heat storage materials are: 
- The demanded melting temperature, which provides operating the TES in a desirable interval of working temperatures.

- High specific thermal capacity, heat of fusion and density to provide the minimum sizes of the TES.

- Congruent melting: PCMs should keep stoichiometric composition in solid and liquid conditions. Otherwise distinction in density of the liquid and solid phase will lead to separation of phases, and, hence, change stoichiometric composition of melt.

- Reliable convertibility at repeated phase transformations.

- High heat conductivity providing the minimum temperature gradients, demanded for charging and discharging the TES.

- The minimum change in volume at transition from one phase in another, that allow us to use simple forms of containers and heat exchangers.

- Insignificant overcooling during hardening.

- Chemical stability providing demanded life time of the TES.

- Compatibility and resistance to oxidation with constructional materials.

- As nontoxic as possible.

- Flame and fire safety.

- Available and cheap.

The lithium carbonate $\left(\mathrm{Li}_{2} \mathrm{CO}_{3}\right)$, an inorganic PCM, corresponds well. Its phase change temperature is $723^{\circ} \mathrm{C}$, in the operation range temperature. Its thermal conductivity is among the best in its class, and its latent enthalpy is relatively high (see Table 1). We made an experimental study using commercial lithium carbonate in order to measure and verify some thermophysical properties such as the temperature of phase change (melting and solidification), the density (solid and liquid) and the undercooling. We used a high temperature furnace (heat up to $1200{ }^{\circ} \mathrm{C}$ ) and a copper cylindrical recipient and thermocouples to make the measures. The interest of using a copper recipient is to check the good chemical compatibility of lithium carbonate and copper at high temperatures.

The results of this experimental study show that the lithium carbonate changes phase in the range $723-732{ }^{\circ} \mathrm{C}$ and the undercooling phenomena is negligible (i.e. we measured a maximum undercooling of $3{ }^{\circ} \mathrm{C}$ ). The results concerning the density are not presented because we observed that the lithium carbonate is porous after solidification. Consequently the density measured is lower than the referenced value. During the heating process, no reaction between lithium carbonate and copper has been observed. After the heating process, the surface of the copper recipient has been oxidized but the lithium carbonate has not been affected by oxidation. Finally, we conclude that lithium carbonate is a component nontoxic, flame safety, and available enough for our application in the range of temperature $100-1000{ }^{\circ} \mathrm{C}$. The lithium carbonate has to be pure, indeed many studies using mixtures of carbonates (containing lithium, sodium and potassium carbonates) show that an addition of a low percentage of another carbonate produces an important decrease of the melting point (see Table 1).

Concerning the metallic matrix, aluminum and copper (see Table 2) has been preliminary chosen because there are often used in such applications. We have also retained iron and stainless steel because their melting temperature is much higher than the operation temperature range of the TES. Among these metals, aluminum is excluded because of its low melting temperature. Regarding the other metals, copper presents the highest thermal conductivity and remains solid until $1,080^{\circ} \mathrm{C}\left(280^{\circ} \mathrm{C}\right.$ more

Table 1: Main properties of PCMs retained for the investigation

\begin{tabular}{|c|c|c|c|c|c|c|c|c|}
\hline $\begin{array}{l}\text { Type of } \\
\text { PCM }\end{array}$ & Material & $\begin{array}{l}\text { Density } \\
\left(\mathrm{kg} / \mathrm{m}^{3}\right)\end{array}$ & $\begin{array}{l}\text { Temperature } \\
\text { of melting } \\
\left({ }^{\circ} \mathrm{C}\right)\end{array}$ & $\begin{array}{l}\text { Latent } \\
\text { enthalpy } \\
(\mathrm{J} / \mathrm{kg})\end{array}$ & $\begin{array}{l}\text { Heat capacity } \\
(\mathrm{J} / \mathrm{kg} \cdot \mathrm{K})\end{array}$ & $\begin{array}{l}\text { Thermal } \\
\text { conductivity } \\
(\mathrm{W} / \mathrm{m} \cdot \mathrm{K})\end{array}$ & $\begin{array}{l}\text { Price } \\
\text { (US\$/kg) }\end{array}$ & Source \\
\hline \multirow[t]{6}{*}{ Inorganic } & $\mathrm{Li}_{2} \mathrm{CO}_{3}$ & 2,110 & $723-732$ & 509,000 & $1,400-2,500$ & 2.6 & $<9$ & {$[19,20]$} \\
\hline & $47 \mathrm{Li}_{2} \mathrm{CO}_{3}-53 \mathrm{~K}_{2} \mathrm{CO}_{3}$ & 2,200 & 488 & 342,000 & $1,030-1,340$ & 1.99 & 1.04 & [19] \\
\hline & $44 \mathrm{Li}_{2} \mathrm{CO}_{3}-56 \mathrm{Na}_{2} \mathrm{CO}_{3}$ & 2,320 & 496 & 370,000 & $1,800-2,090$ & 2.09 & 0.77 & [19] \\
\hline & AlSi12 & 2,700 & 576 & 560,000 & $1,038-1,741$ & 160 & & [19] \\
\hline & $\mathrm{MgCl}_{2}$ & 2,140 & 714 & 452,000 & 970 & n.a. & n.a. & {$[3,21,22,23]$} \\
\hline & $\mathrm{NaCl}$ & 2,160 & 800 & 492,000 & n.a. & 5 & n.a. & \\
\hline \multirow[t]{3}{*}{ Eutectic } & $64 \mathrm{KF}-28 \mathrm{MgaF}-8 \mathrm{NaF}$ & 2,090 & 685 & n.a. & n.a. & n.a. & 0.15 & {$[3,19,21,22,23]$} \\
\hline & $\begin{array}{l}\text { Solar salt } \\
60 \mathrm{NaNO}_{3}-40 \mathrm{KNO}_{3}\end{array}$ & 1,899 & 221 & 161,000 & 1,495 & n.a. & 0.49 & \\
\hline & Hitec & 1,640 & 142 & n.a. & 1,560 & 0.05 & 1.92 & \\
\hline
\end{tabular}


Table 2: Main properties of metals retained for the investigation

\begin{tabular}{llllll}
\hline Material & Density $\left(\mathrm{kg} / \mathrm{m}^{3}\right)$ & $\begin{array}{l}\text { Temperature of } \\
\text { melting }\left({ }^{\circ} \mathrm{C}\right)\end{array}$ & $\begin{array}{l}\text { Heat capacity } \\
(\mathbf{J} / \mathbf{k g} \cdot \mathbf{K})\end{array}$ & $\begin{array}{l}\text { Thermal conductivity } \\
(\mathbf{W} / \mathbf{m} \cdot \mathbf{K})\end{array}$ & Price (US\$/kg) \\
\hline Copper (Cu) & 8,940 & 1,080 & 380 & 392 & 6 \\
Aluminum (Al) & 2,700 & 660 & 660 & 250 & 1.5 \\
Iron (Fe) & 7,874 & 1,538 & 440 & 80 & 0.2 \\
Stainless steel & 7,960 & 1,370 & 450 & 30 & 1.5 \\
\hline
\end{tabular}

than the maximum temperature of the TES) even if it is more expensive and heavier than the others. In addition, its heat capacity is relatively high. Thus, we retain copper mainly because the thermal conductivity is a key parameter in our work since it will affect the heat exchange between TES module and the receiver and thus affect the discharge efficiency of the storage.

Finally lithium carbonate and copper have been selected to be used for the design of the TES module.

\subsection{Choice of a model}

In this paper we propose to use a numerical model which the description of the phase change is inspired from the phase-field method [24] which considers an analogy between the phase change and a kinetic reaction. The aim of the phase-field method is to round the evolution and the transformation of the PCM contrary to the Eq. (4) which imposes a discontinuous function. In order to simplify the phase field method we decide to lead the reaction with a unique kinetic constant of reaction called $\beta$. This parameter is the one which can vary in order to adapt the model to the experimental results. Varying the parameter $\beta$ (from $10^{-4}$ to $10^{-1}$ ) has a great influence on the accuracy of the results but also on the computation time. A previous value of $\beta$ can be estimated from the phase field method which takes into account a lot of parameters such as the geometry of the TES. This method leads us to choose $\beta=0.001 \mathrm{~K}^{-1} \cdot \mathrm{s}^{-1}$.

Thus we describe the phase change by coupling the heat transfer equation with an equation of diffusion. The heat equation manage the heat transfer by conduction and convection taking into account the additional heat source due to the PCM with the variable Q $\left(\mathrm{W} / \mathrm{m}^{3}\right)$ in Eq. (8). The diffusion equation is a mass transfer equation based on the analogy of a kinetic formulation using the kinetic constant $\beta$ described before.

$$
\left\{\begin{array}{l}
\rho C_{p} \frac{\partial T}{\partial t}+Q=\lambda \Delta(T) \\
\frac{\partial f_{l}}{\partial t}=\beta\left(T-T_{m}\right) f_{l}
\end{array}\right.
$$

$$
\left\{\begin{array}{l}
\rho=\rho_{\text {sol }} \times\left(1-f_{l}\right)+\rho_{l i q} \times f_{l} \\
C p=C p_{\text {sol }} \times\left(1-f_{l}\right)+C p_{l i q} \times f_{l} \\
\lambda=\lambda_{\text {sol }} \times\left(1-f_{l}\right)+\lambda_{l i q} \times f_{l}
\end{array}\right.
$$

The coupling is provided by the definition of the heat source term $Q=\rho L\left(\partial f_{l} / \partial t\right)$. The evolution of the fraction of liquid $\operatorname{PCM}\left(\partial f_{l} / \partial t\right)$ is then formulated in the mass transfer equation of diffusion. It is important to remark that $\partial f_{l} / \partial t$ is positive for the melting ( $f_{l}$ grows) and negative for the solidification ( $f_{l}$ decreases). In order to enhance the accuracy of the model we decide to add variable thermophysical properties of the PCM. To formulate this, we use an average formulation like Bhattacharya [16] between the solid value and the liquid value according the fraction of liquid $\mathrm{f}_{1}$ (Eqs. (10), (11) and (12)).

\subsection{Description of the system, steady state analysis}

The studied system implements a very simple geometry which consists of a one meter cubic copper matrix drilled with tubes of lithium carbonate. The arrangement of these cylinders and there diameter, directly linked to the volume fraction of PCM into the TES, is studied. The copper matrix must intensify the apparent thermal conductivity of the TES whereas PCM is used to enhance the storage capacity.

The model of TES is inspired from the last method mentioned of the metallic matrix [13]. While the honeycomb wallboard presents multitude of hexagonal cavities, we investigate a model composed by a cubic metallic matrix drilled by some cylindrical hole filled with the PCM. Our model presents less surface exchange than a honeycomb structure but has the advantage of an easier manufacture and a cheaper cost.

So a numerical model is developed, using CDF software, in order to determine the performances of the TES according to the geometry and the ratio $\mathrm{PCM} / \mathrm{metallic}$ matrix. Before designing a TES, it is important to have an idea of the quantity of material useful, and the thermal 
a)

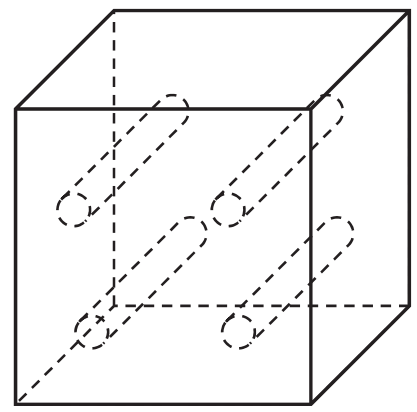

b)

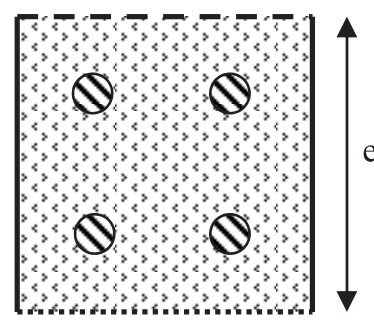

Legends:

- - $\quad 800^{\circ} \mathrm{C}$

$600{ }^{\circ} \mathrm{C}$

Insulated

Metal

PCM

Fig. 3: Isometric view (a) and face view (b) of the TES model, subdomains and border conditions

behavior of the system when the TES is under operation. Fig. 3 shows how the model looks like.

The TES is represented in two dimensions by a $1 \mathrm{~m}^{2}$ surface ("e" is the characteristic dimension of 1 meter) of copper drilled with tubes of lithium carbonate. The top side is submitted to a temperature of $800{ }^{\circ} \mathrm{C}$ and the bottom surface to $600^{\circ} \mathrm{C}$ in order to generate a heat transfer flux from the upper to the bottom side. The circles are perpendicular to the heat flux. Other sides are insulated. Inner boundaries are frontiers of continuity, means that there is nothing between the copper and the lithium carbonate.

\subsection{Analysis method, use of the equivalent thermal conductivity}

At first the following assumption is done: the heat transfer flux through our system is du to the only conduction, which is a relevant assumption regarding our system configuration. Then, considering a unique thermal conductivity for the entire system, nammed equivalent (i.e. apparent) $\lambda_{e q}$, the density of heat flux $\varphi\left(\mathrm{W} / \mathrm{m}^{2}\right)$ crossing the system can be written as follows:

$$
\varphi\left(W / m^{2}\right)=\frac{\lambda_{e q}}{e} \Delta T
$$

where e is the characteristic dimension of the TES of $1 \mathrm{~m}$, and $\Delta \mathrm{T}$ (in $\mathrm{K}$ ) is the difference of temperature between the upper and the bottom side.

In order to estimate the quality of the geometry, the expression of the equivalent thermal conductivity is extracted from Eq. (13):

$$
\lambda_{e q}=\frac{\varphi \cdot e}{\left(T_{\text {high }}-T_{\text {down }}\right)}
$$

where $\mathrm{T}_{\text {high }}-\mathrm{T}_{\text {down }}$ defined the difference of temperature of $200 \mathrm{~K}$ between the upper and the down surfaces.

In this equation (Eq. (14)), $\lambda_{e q}$ only depends on the heat flux ( $\varphi$ in $\mathrm{W} / \mathrm{m}^{2}$ ), because e, $\mathrm{T}_{\text {high }}$ and $\mathrm{T}_{\text {down }}$ are fixed before performing the simulation. $\mathrm{T}_{\text {high }}-\mathrm{T}_{\text {down }}$ is the difference of temperature of $200 \mathrm{~K}$ between the upper and the down surfaces.

Finally, the heat flux $\varphi$ is calculated by the software at each point of the mesh and averaged among the entire geometry. Note that each arrangement of tubes in the geometry gives a different heat flux. Then, knowing the imposed temperature $\mathrm{T}_{\text {high }}$ and $\mathrm{T}_{\text {down }}$ and knowing the characteristic dimension e, the equivalent thermal conductivity defined in the Eq. (14) is calculated for each geometry. The higher is the equivalent thermal conductivity, the greater is the efficiency of the tested arrangement of tubes in terms of release power of thermal energy.

\section{Thermal behavior analysis of the system at steady state}

A parametric study is performed using the equivalent thermal conductivity as a comparison parameter. The influence of the following parameters on the equivalent thermal conductivity is analyzed:

- The volume fraction of PCM in the copper matrix;

- The number of cylinder in height;

- The number of cylinder in width;

- The position of the cylinder (quincunx or not).

As a mathematical matrix, lines are horizontal and columns are vertical. Geometries are so referenced by an index containing three parameters: (number of lines, number of columns, volume fraction of PCM). For example, the geometry $(3,5,30)$ corresponds to a TES composed of 3 lines and 5 columns of PCM tubes (i.e. 15 tubes) and a 
Table 3: Main characteristics used for the parametric study

\begin{tabular}{llll}
\hline Properties & $\mathrm{Cu}$ & \multicolumn{2}{c}{$\mathrm{Li}_{2} \mathrm{CO}_{3}$} \\
\cline { 3 - 4 } & & Solid & Liquid \\
\hline Density $\rho\left(\mathrm{kg} / \mathrm{m}^{3}\right)$ & 8,940 & 2,110 & 2,110 \\
Thermal conductivity $\lambda(\mathrm{W} / \mathrm{m} \cdot \mathrm{K})$ & 392 & 2.6 & 2.6 \\
Heat capacity $\mathrm{Cp}(\mathrm{J} / \mathrm{kg} \cdot \mathrm{K})$ & 385 & 1,800 & 2,500 \\
Latent heat $\mathrm{L}(\mathrm{J} / \mathrm{kg})$ & n.a. & \multicolumn{2}{c}{509,000} \\
Melting temperature $\mathrm{T}_{\mathrm{m}}(\mathrm{K})$ & n.a. & \multicolumn{2}{c}{$996\left(723^{\circ} \mathrm{C}\right)$} \\
\hline
\end{tabular}

Model 2D

Kinetic constant $\beta\left(\mathrm{K}^{-1} \cdot \mathrm{s}^{-1}\right) \quad 0.001$

Mesh Refine

global volume fraction of PCM of $30 \%$. The properties used for the parametric study are shown in Table 3.

\subsection{Variation of the PCM volume fraction}

The first parameter studied is the variation of PCM volume fraction in the storage. We compare geometries made with 9 cylinders (3 lines by 3 columns) and rates from 30\% to $70 \%$. As an example, Fig. 4 shows two of these geometries, model (a) with $30 \%$ PCM, and model (b) with $70 \%$ of PCM.

The equivalent thermal conductivity is so limited by two extreme values: the thermal conductivity of copper of $392 \mathrm{~W} / \mathrm{m} \cdot \mathrm{K}$ and the thermal conductivity of lithium carbonate of $2.6 \mathrm{~W} / \mathrm{m} \cdot \mathrm{K}$. The radius of tubes evolves according to the fraction of PCM. For each geometry, the radius of PCM tubes is calculated and the tubes are placed in a symmetric way in the copper matrix. The CFD software calculates the temperature at each intersection mesh and then integrates the entire geometry to give a unique value of the heat flux $\varphi\left(\mathrm{W} / \mathrm{m}^{2}\right)$ crossing the system. Then we obtain the equivalent thermal conductivity from Eq. (14). In Fig. 5 , the evolution of the equivalent thermal conductivity according to the volume fraction of PCM is plotted.

The results in Fig. 5 give a linear evolution of the equivalent thermal conductivity according to the volume fraction of PCM. Increasing the volume fraction of PCM causes a linear decrease of the equivalent thermal conductivity because of the relatively low thermal conductivity of the PCM. The extremums of this curve are a conductivity of $392 \mathrm{~W} / \mathrm{m} \cdot \mathrm{K}$ if there is no PCM (i.e. the conductivity of copper) and $2.6 \mathrm{~W} / \mathrm{m} \cdot \mathrm{K}$ for a volume fraction of $100 \%$ (i.e. the conductivity of the lithium carbonate). The same investigation have been lead with others geometries with as many lines as columns (geometries $(6,6)$ and $(9,9)$ ) and the same linear evolution of the equivalent thermal conductivity were obtained.

So the equivalent thermal conductivity is directly linked to the volume fraction of PCM. A great amount of PCM results in a high storage capacity and a low thermal conductivity whereas a small fraction of PCM maintains a high equivalent thermal conductivity but a low storage capacity.

\subsection{Influence of the number of lines}

The influence of the number of lines is studied, keeping the volume fraction of PCM constant at $30 \%$ and a number of columns of 3. We make the number of lines evolving from 2 to 7 . This has for consequence the change of the radius of the PCM tubes. Indeed the radius evolves from $126 \mathrm{~mm}$ for 2 lines until $67 \mathrm{~mm}$ for 7 lines. Like previously, the CFD software integrates the temperature on the entire geometry to calculate the heat transfer flux through the system. The curve in Fig. 6 gives the results obtained.

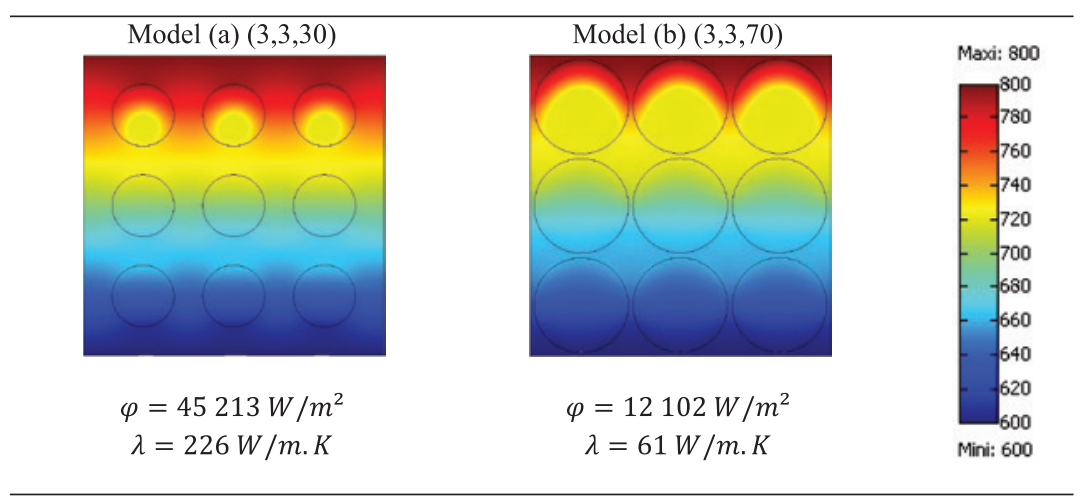

Fig. 4: Influence of the increase of the PCM tube's radius on the heat transfer and thermal conductivity 


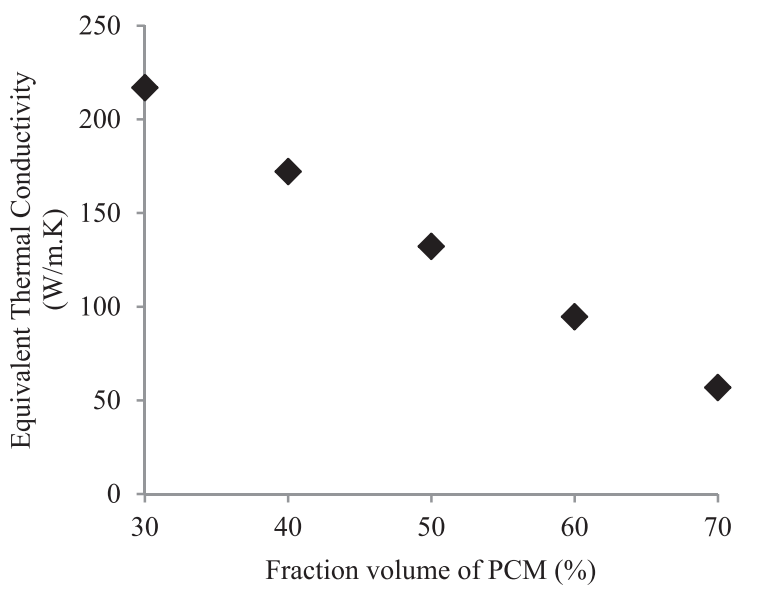

Fig. 5: Influence of the volume fraction of PCM, number of lines and columns constant

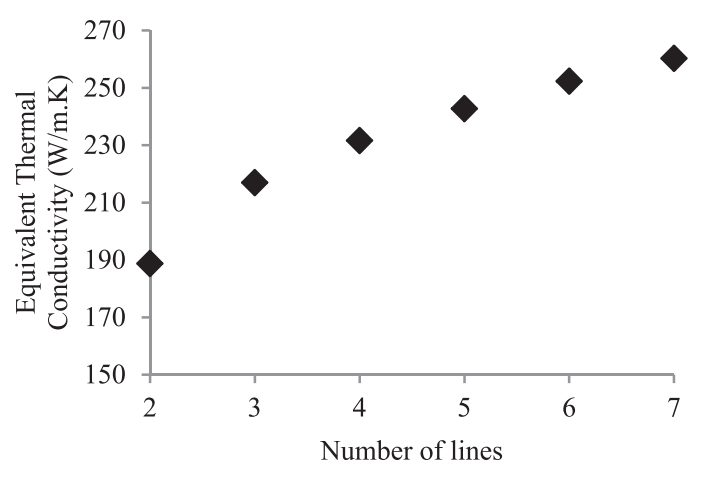

Fig. 6: Influence of the number lines, volume fraction of PCM and number of columns constant

Fig. 6 shows that the equivalent thermal conductivity increases with the number of lines. From the numerical data, we can conclude that moving from two lines to three lines causes a gain of $12 \%$ for the conductivity. Adding an extra line gives a gain of between 3 and $6 \%$. Indeed the addition of an extra line (keeping the PCM volume fraction constant) implies the reduction of the tube's radius and the heat transfer is improved in the tube.

\subsection{Influence of the number of columns}

The influence of the number of columns is studied, keeping the volume fraction of PCM constant at 30\% and a number of lines of 3 . We make the number of columns evolving from 2 to 7 . This has the same consequence than in the previous paragraph on the radius of the PCM tubes. The CFD software still integrates the temperature on the

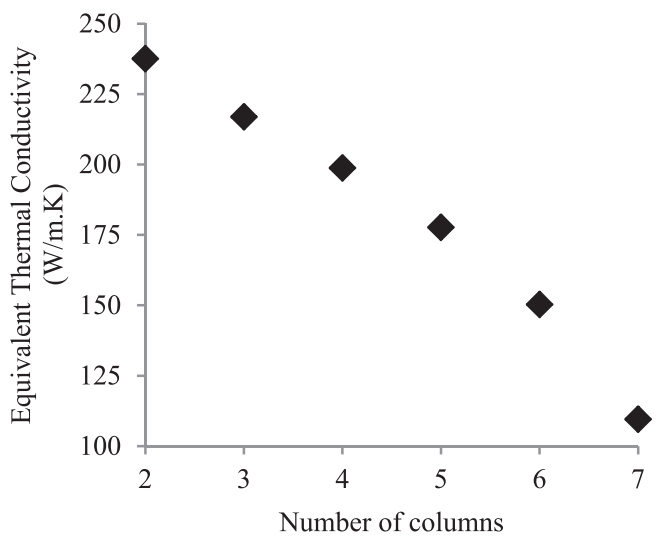

Fig. 7: Results studying the increase of the number columns

entire geometry to calculate the heat transfer flux through the system. The curve in Fig. 7 gives the results obtained.

Fig. 7 shows that increasing the number of columns causes a decrease of the equivalent thermal conductivity. From the numerical data, we can conclude that the addition of an extra line causes a decrease of 9\% until 37\% for the passage of 6 columns to 7 .

Sections 3.2 and 3.3 lead to conclude that the space between two columns is important for the diffusion of the heat transfer flux through the system. The space between lines, on the contrary, must be minimized. We can so define what we call "path of thermal flow" which is the section normal to the heat transfer direction composed of only copper. In order to verify this hypothesis we study in the following section the importance of these paths of flow.

\subsection{Importance of the paths of flow}

To study the paths of flow influence, we investigate two geometries with the same volume fraction of PCM (30\%). Each geometry consists 7 lines and 3 columns of PCM tubes. In the first one, tubes are arranged one below the others in order to have some path of flow. In the second one, tubes are arranged in quincunx in order to struggle the flow of the heat flux. Fig. 8 shows both geometries described.

The results, obtained by the same process as before, confirm the hypothesis made in the previous paragraph: with the first geometry, the equivalent thermal conductivity equals to $264 \mathrm{~W} / \mathrm{m} \cdot \mathrm{K}$ whereas it equals $235 \mathrm{~W} / \mathrm{m} \cdot \mathrm{K}$ in the second geometry with tubes in quincunx. The diminution of $11 \%$ confirms that it is important to have an arrangement of tubes allowing columns and path of flow. 


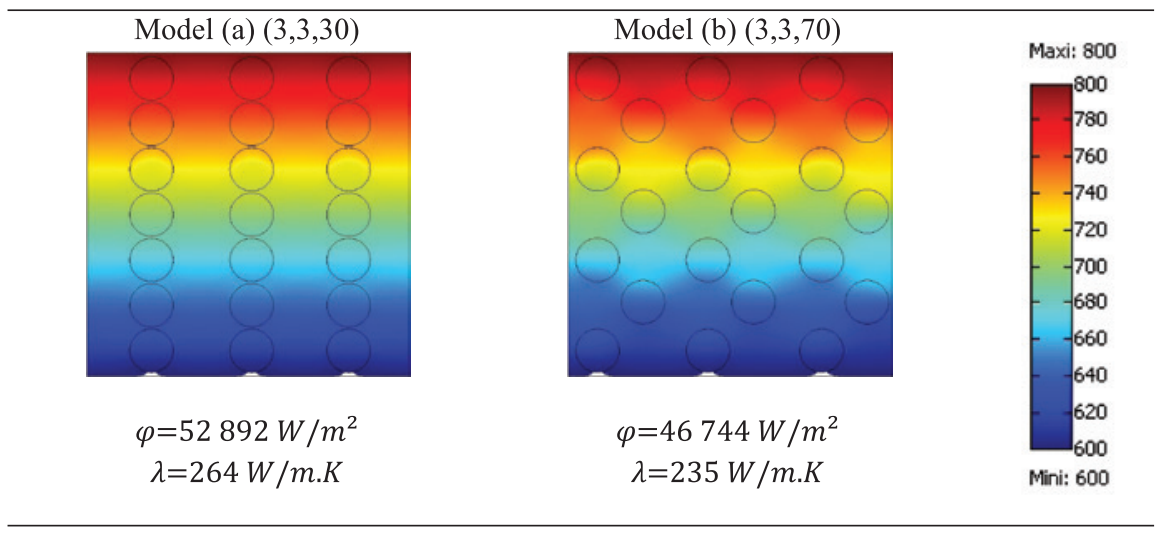

Fig. 8: Influence of paths of flow on the heat transfer and thermal conductivity

\section{Design of an optimized geometry}

\subsection{Describing the influence of the whole geometry on the heat transfer into the system}

Until now, two parameters were identified in order to describe the TES thermal behavior:

- The PCM volume fraction, $\tau_{\mathrm{PCM}}$, which represents the thermal storage capacity;

- The equivalent thermal conductivity, $\lambda_{\text {eq }}$, which represents the power of the TES.

However, none of them is able to describe the influence of the whole geometry in the system. Indeed, with a unique volume fraction of PCM we can have various geometries (i.e. different arrangement of lines and columns) with the same equivalent thermal conductivity but not the same storage capacity (i.e. the PCM volume fraction). This fact is illustrated in Fig. 9, where we have plotted the evolution of the equivalent thermal conductivity according to the PCM volume fraction for three geometries performed into the CFD software. At a PCM volume fraction of $30 \%$ for example, the three geometries have the same equivalent thermal conductivity situated around $220 \mathrm{~W} / \mathrm{m} \cdot \mathrm{K}$.

Hence, regarding the high difference between the thermal conductivities of copper and lithium carbonate, a unique geometric parameter is determined, able to describe the arrangement of lines and columns, taking into account the PCM volume fraction and the influence of the geometry on the heat transfer. This parameter, called "cross section coefficient" and mentioned as CSC, represents the cross section offered to the heat transfer flux between the cylinders. Indeed the heat flux crosses the

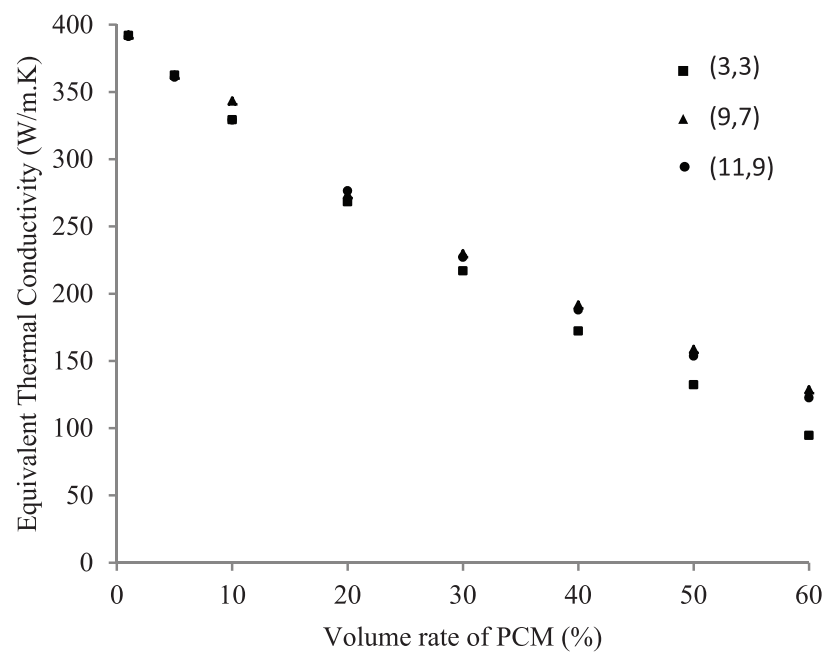

Fig. 9: Evolution of $\lambda_{\text {eq }}$ according to PCM volume fraction

TES mostly into the copper whereas the lithium carbonate tubes act as a thermal barrier. So we calculate the width allowing the flux to cross (red double arrows).

The cross section coefficient corresponds to the addition of the red double arrows. To calculate this, we subtract the sum of the tube diameters $\left(2 . R_{P C M}\right)$ from the width of the module "l", as shown in Fig. 10, thus:

$$
C S C=l-n_{c} \cdot 2 \cdot R_{P C M}
$$

Then we calculate the radius of tube, $\mathrm{R}_{\mathrm{PCM}}$, from the fraction of PCM, $\tau_{\mathrm{PCM}}$ :

$$
\begin{gathered}
\tau_{P C M}=\frac{V_{P C M}}{V_{\text {tot }}}=\frac{S_{P C M}}{S_{\text {tot }}}=\frac{n_{c} n_{l} \pi R_{P C M}^{2}}{S_{\text {tot }}} \\
R_{P C M}=\sqrt{\frac{\tau_{P C M} \cdot S_{t o t}}{\pi \cdot n_{l} \cdot n_{c}}}
\end{gathered}
$$




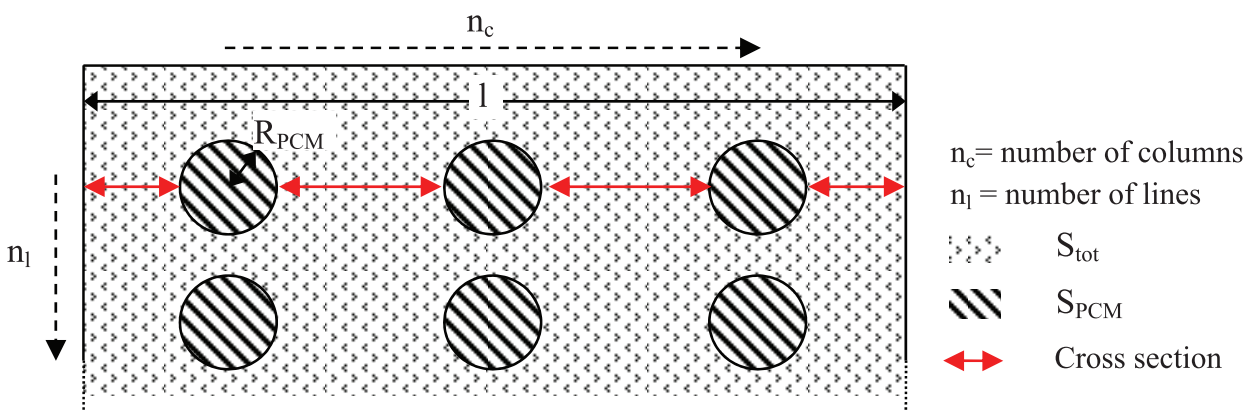

Fig. 10: Illustration for the calculation of the cross section coefficient

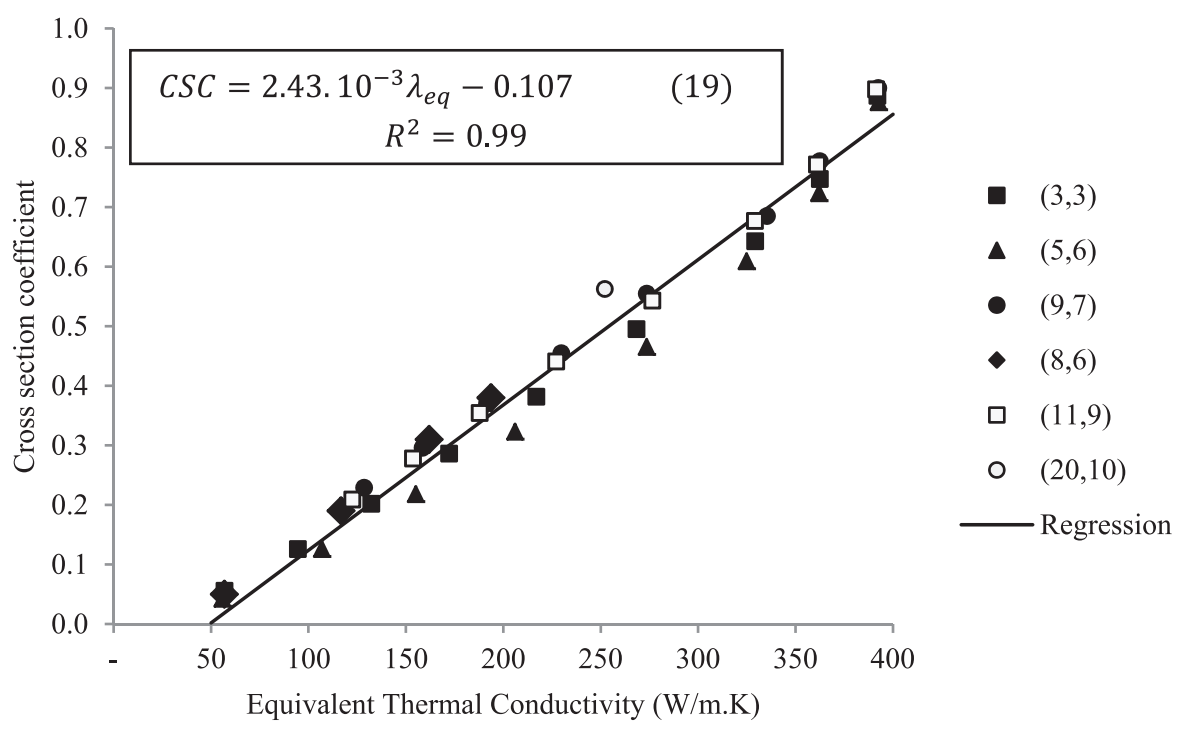

Fig. 11: Evolution of CSC according to $\lambda_{\text {eq }}$, and linear regression

Replace the expression of $\mathrm{R}_{\mathrm{PCM}}$ in the Eq. (15), it becomes:

$$
C S C=l-2 \sqrt{\frac{\tau_{P C M} \cdot n_{c} \cdot S_{t o t}}{\pi \cdot n_{l}}}
$$

Hence, it is possible to calculate the value of the cross section coefficient for various geometries and thus to establish the variation of this coefficient as a function of the equivalent thermal conductivity (Fig. 11). We observe that there is a linear correlation between these two parameters. This proves that whatever the proposed geometric configuration, the equivalent thermal conductivity is the same as long as the cross section coefficient is the same. In other words, the influence of the geometric configuration (arrangement and number of lines and columns) on the conductive heat transfer in the system can be described by a unique parameter, the cross section coefficient.

The cross section coefficient is so a parameter than can be substituted to the equivalent thermal conductivity which needs CFD software to be determined. On the contrary, the cross section coefficient can be calculated very easily knowing the geometry parameters. In the following section, a methodology is given to determine the optimized geometry from primary choices.

\subsection{Methodology, choice of an optimized geometry}

\subsubsection{Build of a design/optimization tool}

It is now possible to determine which geometry is the best among a panel only by calculating the cross section coefficient (CSC). Thanks to a simple Matlab ${ }^{\circledR}$ code, a three dimensions matrix containing all CSC values, calculated from the number of lines, the number of columns (both evolving from 1 to 50), and the PCM volume fraction (evolving from 1 to $78 \%$ ) is established. For this, a first 


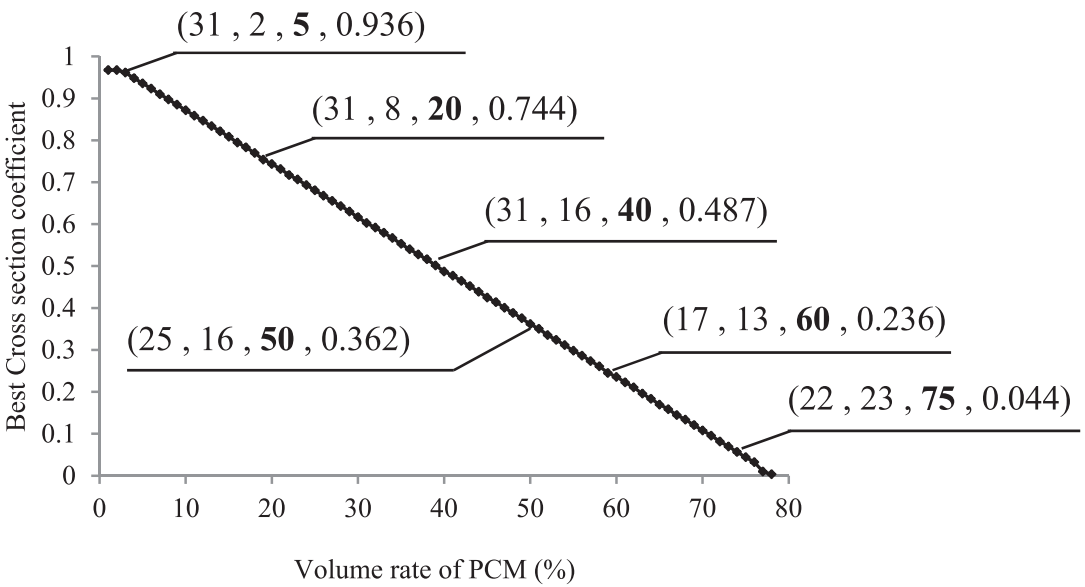

Fig. 12: Best cross section coefficient according to the PCM volume fraction

function, using iteration with the three parameters, calculates the PCM tubes radius. Then the code tests if the geometry is consistent. Indeed it can happen that the sum of the tubes dimensions exceeds the whole TES size. Once the arrangement is validated, the CSC is calculated and stored in the matrix at its proper place. Then a second function searches the best CSC for each PCM volume fraction, from 1 to $78 \%$, and stores the number of lines and columns. Fig. 12 shows the best geometries found, the boxes on the curve show few examples of optimized geometries. The following nomenclature is used to characterize the geometries:

(number of lines, number of columns, PCM volume fraction, cross section coefficient)

For example, a TES module with a PCM volume rate of $50 \%$ is needed; the best geometry (i.e. optimizing the conductive heat transfer) should be an arrangement of 25 lines, 16 columns and a CSC of 0.362 .

We observe that the evolution of the best CSC is linear according to the PCM volume fraction. It evolves from 1 (i.e. a majority of metal) to 0 (a majority of PCM). It is important to notice that for each percentage of PCM volume fractions Fig. 12, the arrangement of lines and columns is not necessarily the same as shown in the different boxes presented.

By varying the number of lines and columns from 1 to 50 , we observe that the optimized arrangement of tubes never exceed 31 tubes. The second observation concerns the number of lines which is always higher or equals to the number of columns. That confirms one more time that it is primordial to keep the path of flow by choosing a number of lines higher than the number of columns.

\subsubsection{Utilization of the design tool}

The methodology proposed is this paper is the following:

1. The user defines his needs in terms of storage capacity E (Joules).

2. This storage capacity, lead to calculate the mass of PCM and copper considering the sensible and latent heat of both material and the available volume for the TES. The solution is given by the resolution of the following equations system:

$$
\left\{\begin{array}{c}
E=m_{P C M}\left(C p_{\text {sol }}\left(T_{m}-T_{\text {down }}\right)+L+C p_{\text {liq }}\left(T_{\text {high }}-T_{m}\right)\right) \\
\quad+m_{C u} C p_{C u}\left(T_{\text {high }}-T_{\text {down }}\right) \\
V_{\text {total }}=V_{c u}+V_{P C M} \stackrel{\text { equivalent to }}{\Longleftrightarrow} S_{\text {exchange }} \times e=\frac{m_{C u}}{\rho_{C u}}+\frac{m_{P C M}}{\rho_{P C M}}
\end{array}\right.
$$

The solution of this system is:

$$
\left\{\begin{array}{c}
m_{P C M}=\rho_{P C M} \frac{\rho_{C u} C p_{C u}\left(T_{\text {high }}-T_{\text {down }}\right) S_{\text {exchange }} \times e-E}{\rho_{C u} C p_{C u}\left(T_{\text {high }}-T_{\text {down }}\right)-\rho_{P C M}\left(C p_{\text {solid }}\left(T_{\text {melt }}-T_{\text {down }}\right)+L+C p_{\text {liquid }}\left(T_{\text {high }}-T_{\text {melt }}\right)\right)} \\
m_{P C M}=\rho_{C u}\left(S_{\text {exchange }} \times e-\frac{m_{P C M}}{\rho_{P C M}}\right)
\end{array}\right.
$$

3. The PCM volume fraction in the storage is calculated thanks to:

$$
\tau_{P C M}=\frac{m_{P C M}}{\rho_{P C M}} \times \frac{1}{V_{\text {total }}}
$$

4. Finally, thanks to data provided in Fig. 12, the best cross section coefficient is calculated and the optimized arrangement of lines and columns is established. Thus, an optimized geometry has been designing, as regard to the equivalent conductive thermal 
behavior through the system. In addition, the equivalent conductive thermal behavior can be characterized by calculating the value of the equivalent conductivity of the system using data provided in Fig. 11.

\subsubsection{Case study and validation}

In this section, the methodology is used in a case study.

1. By performing a geometrical integration on Fig. 2, the needs in terms of energy storage are estimated to about $77 \mathrm{MJ}$.

2. In the case of Pegase solar receiver, the exchange surface is $1.28 \mathrm{~m}^{2}$ while the space available back to receiver is about $6.5 \mathrm{~cm}$. So the mass of copper and PCM are calculated thanks to Eq. (21) and materials properties mentioned in Tables 1 and 2. The solution is:

$$
\begin{aligned}
& m_{P C M}=33 \mathrm{~kg} \\
& m_{C u}=604 \mathrm{~kg}
\end{aligned}
$$

3. The PCM volume fraction corresponding to these masses is:

$$
\tau_{P C M}=\frac{m_{P C M}}{\rho_{P C M}} \frac{1}{V_{\text {total }}}=\frac{33}{2110} \frac{1}{1.28 \times 0.065}=19 \%
$$

Thanks to Figs. 11 and 12, this PCM volume fraction of $19 \%$ leads to a CSC of 0.75 corresponding to an arrangement of tubes composed of 13 lines and 3 columns. The equivalent thermal conductivity of this geometry is $328 \mathrm{~W} / \mathrm{m} \cdot \mathrm{K}$.

The validation of the methodology consists in the calculation of the average power that the TES can provide. From Fig. 2, the average power required to satisfy our constraint (temperature decrease at the outlet of the receiver less than $150^{\circ} \mathrm{C}$ after 15 minutes without any solar contribution) has been calculated at $80 \mathrm{~kW}$.

Then to validate the optimized geometry of the TES that we have just designed, we should check that the conductive heat transfer through the TES will not be limiting phenomenon. Thus, using the equivalent conductivity, we can estimate power flux through the TES due to conductive heat transfer:

$$
\begin{gathered}
P_{T E S}(W)=\frac{\lambda_{\text {equivalent }}}{e} S_{\text {exchange }} \Delta T_{\text {average }} \\
P_{T E S}(W)=\frac{328}{0.065} \times 1.28 \times 140=900 \mathrm{~kW}
\end{gathered}
$$

The power transferred by equivalent conduction is greater than the average power required. This means that the conduction through the TES is not limiting and that the proposed geometry is suitable for our application.

Of course, other physical phenomenon occurs in such a system and even if the conductive heat transfer will not limit the efficiency of the system, the global power transferred will be less than the previous calculated value, due to heat transfer resistance that we not consider in this study (contact resistance between PCM and copper for instance). Nevertheless, regarding the only conductive effect, the proposed method allows comparing geometries and finally to design the best geometry (i.e. the best arrangement of the PCM tubes in the copper matrix) as regard to the heat transfer in such a TES system.

\section{Conclusion}

In this paper, an innovative kind of protecting thermal energy storage technology is investigated, based on the coupling of a conductive matrix with phase change materials. Considering the specifications of an existing new solar receiver (Pegase project) a very simple TES architecture is developed, composed of a metallic copper matrix (for the power of storage) drilled with tubes of phase change material (for the storage capacity), the lithium carbonate.

Then a numerical model at steady state is used in order to optimize the geometry of the system as regard to the conductive heat transfer through the TES module. A parametric study allows to highlight the importance of a unique geometrical parameter, called "cross section coefficient", able to describe the influence of the whole arrangement on the power transferred by conduction. Finally, an appropriate methodology integrating this geometrical parameter is developed in order to bring out an optimized geometry of the TES module. This method permits to design the best arrangement of the PCM tubes in the copper matrix, i.e. to find out the geometry allowing the greater conductive heat transfer.

\section{Nomenclature}

\section{Greek symbols}

$\beta$

$\begin{array}{ll}\lambda, \lambda_{\text {eff }}, \lambda_{\text {eq }} & \text { Thermal conductivity }(\mathrm{W} / \mathrm{m} \cdot \mathrm{K}) \\ \rho & \text { Density }\left(\mathrm{kg} / \mathrm{m}^{3}\right) \\ \varphi & \text { Heat flux in the TES model }\left(\mathrm{W} / \mathrm{m}^{2}\right) \\ \tau_{\text {PCM }} & \text { Volume fraction of PCM }\end{array}$




\section{Latin symbols}

$\begin{array}{ll}\mathrm{Cp}, \mathrm{Cp}_{\mathrm{e}} & \text { Heat capacity }(\mathrm{J} / \mathrm{kg} \cdot \mathrm{K}) \\ \mathrm{e} & \text { Characteristic dimension of the TES }(\mathrm{m}) \\ \mathrm{f}_{\mathrm{l}} & \text { Liquid fraction of PCM }(\%) \\ \mathrm{h} & \text { Enthalpy per volume unit }\left(\mathrm{J} / \mathrm{m}^{3}\right) \\ \mathrm{l} & \text { Width of the TES geometry }(\mathrm{m}) \\ \mathrm{L} & \text { Latent heat of fusion }(\mathrm{J} / \mathrm{kg}) \\ \mathrm{m} & \text { mass }(\mathrm{kg}) \\ \mathrm{n}_{\mathrm{c}}, \mathrm{n}_{\mathrm{l}} & \text { Number of columns or lines } \\ \mathrm{P} & \text { Source term of energy }\left(\mathrm{J} / \mathrm{m}^{3}\right) \\ \mathrm{Q} & \text { Source term of energy }\left(\mathrm{W} / \mathrm{m}^{3}\right) \\ \mathrm{R}_{\mathrm{PCM}} & \text { Radius of PCM tubes }(\mathrm{m}) \\ \mathrm{S}_{\mathrm{PCM}}, \mathrm{S}_{\text {tot }} & \text { Section of PCM tubes or TES }\left(\mathrm{m}^{2}\right) \\ \mathrm{t} & \text { Time (s) } \\ \mathrm{T}_{1} \mathrm{~T}_{\mathrm{m}} & \text { Temperature }\left(\mathrm{K} \text { or }{ }^{\circ} \mathrm{C}\right) \\ \mathrm{V}_{\mathrm{PCM}}, \mathrm{V}_{\text {tot }} & \text { Volume of PCM tubes or TES }\left(\mathrm{m}^{3}\right)\end{array}$

$\begin{array}{ll}\text { Abbreviations } \\ \text { CFD } & \text { Computational Fluid Dynamics } \\ \text { CRS } & \text { Central Receiver System } \\ \text { CSC } & \text { Cross Section Coefficient } \\ \text { CSP } & \text { Concentrated Solar Power } \\ \text { DSG } & \text { Direct Steam Generation } \\ \text { HSGT } & \text { Hybrid Solar Gas Turbine } \\ \text { HTF } & \text { Heat Transfer Fluid } \\ \text { PCM } & \text { Phase Change Material } \\ \text { PEGASE } & \text { Production of Electricity from Gas and Solar } \\ & \text { Energy } \\ \text { SEGS } & \text { Solar Energy Generating Systems } \\ \text { TES } & \text { Thermal Energy Storage }\end{array}$

\section{Organizations}

ADEME Agence de l'Environnement et de la Maîtrise de l'Energie

CNRS Centre National de la Recherche Scientifique EDF Electricité de France

Received: August 23, 2013. Accepted: December 7, 2013.

\section{References}

[1] N. Calvet, X. Py, J.-P. Dumas, "Stockage thermique performants et durables pour procédés solaires : des basses aux hautes températures", rapport de thèse, octobre 2010.

[2] M. Farid, A. Khudhair, S. Razack, S. Al-Hallaj, "A review on phase change energy storage: materials and applications", Energy Conversion and Management 45 (2004) 1597-1615.

[3] B. Zabla, J. Marin, L. Cabeza, H. Mehling, "Review on thermal energy storage with phase change material, heat transfer analysis and applications", Applied Thermal Engineering 23 (2003) 251-283.
[4] V. Shatikian, G. Ziskind, R. Letan, "Numerical investigation of a PCM-based heat sink with internal fins: constant heat flux", International Journal of Heat and Mass Transfer 51 (2008) 1488-1493.

[5] X. Py, R. Olivès, S. Mauran, "Paraffin/porous-graphite-matrix composite as a high and constant power thermal energy storage material”, International Journal of Heat and Mass Transfer 44 (2001) 2727-2737.

[6] A. Mills, M. Farid, J. R. Selman, S. Al Hallaj, "Thermal conductivity of phase change materials using a graphite matrix", Applied Thermal Engineering 26 (2006) 1652-1661.

[7] S. Pincemin, X. Py, R. Olives, M. Christ, "Highly conductive composites made of phase change materials and graphite for thermal storage", Solar Energy Materials and Solar Cells, 92 (2008) 603-613.

[8] M. M. Alkilani, K. Sopian, M. A. Alghoul, M. Sohif, M.H. Rulsan, "Review of solar air collectors with thermal storage units", Renewable and Sustainable Energy Reviews 15 (2011) 1476-1490.

[9] W. Saman, Bruno, E. Halawa, "Thermal performance of PCM thermal storage unit for a roof integrated solar heating system", Solar Energy 78 (2005) 341-349.

[10] H. Zhang, X. Wang, D. Wu, "Silica encapsulation of n-octadecane via sol-gel process: A novel microencapsulated PCM with enhanced thermal conductivity and performance", Energy Journal of Colloid and Interface Science 343 (2010) 246-255.

[11] M. Zukowski, "Mathematical modeling and numerical simulation of a short term thermal energy storage system using phase change material for heating applications", Energy Conversion and Management 48 (2007) 155-165.

[12] E. Onder, N. Sarier, E. Cimen, “Encapsulation of phase change materials by complex coacervation to improve thermal performances of woven fabrics", Thermochimica Acta 467 (2008) 63-72.

[13] C. Hasse, M. Grenet, A. Bontemps, R. Dendievel, H. Sallée, "Realization, test and modeling of honeycomb wallboards containing a phase change material", Energy and Buildings 43 (2011) 232-238.

[14] G. Hed, R. Bellander, "Mathematical modeling of PCM air heat exchanger", Energy and Building 38 (2006) 82-89.

[15] P. Dolado, A. Lazaro, J. M. Marin, B. Zabla, “Characterization of melting and solidification in a real scale PCM-air heat exchanger: Numerical model and experimental validation", Energy Conversion and Management 52 (2011) 1890-1907.

[16] M. Bhattacharya, T. Basak, K. G. Ayappa, "A fixed-grid finite element based enthalpy formulation for generalized phase change problems: role of superficial mushy region", International Journal of Heat and Mass Transfer 45 (2002) 4881-4898.

[17] Y. Dutil, D. R. Rousse, N. Ben Salah, S. Lassue, L. Salewski, "A review on phase-change materials: Mathematical modeling and simulations", Renewable and Sustainable Energy Reviews 15 (2011) 112-130.

[18] B. Grange, « Modélisation et dimensionnement d'un récepteur solaire à air pressurisé pour le projet PEGASE », Rapport de thèse (2012).

[19] M. M. Kenisarin, "High temperature phase change materials for thermal energy storage", Renewable and Sustainable Energy Reviews 14 (2010) 955-970. 
[20] G. J. Janz, M. R. Lorenz, "Solid-liquid phase equilibria for 26 mixtures of lithium, sodium, and potassium carbonates", Journal of Chemical and Engineering Data 6 (1961) 321-323.

[21] X. Wang, J. Liu, Y. Zhang, H. Di, Y. Jiang, “Experimental research on a kid of novel high temperature phase change storage heater", Energy Conversion and Management 47 (2006) 2211-2222.

[22] National Renewable Energy Laboratory, website: http://www.nrel.gov

[23] Archimede Solar Energy, website: http://www. archimedesolarenergy.com

[24] N. Calvet, X. Py, R. Olivès, J. P. Bédécarrats, J. P. Dumas, F. Jay, "Enhanced performances of micro-encapsulated phase change materials by intensification of the internal effective thermal conductivity”, Energy (2013).

\section{Appendix: Best arrangement of tubes into the TES according to the PCM volume fraction}

\begin{tabular}{|c|c|c|c|c|c|}
\hline \multirow{2}{*}{$\begin{array}{l}\text { PCM's } \\
\text { volume } \\
\text { rate }\end{array}$} & \multicolumn{2}{|c|}{$\begin{array}{l}\text { Optimized number } \\
\text { of }\end{array}$} & \multirow[t]{2}{*}{$\begin{array}{l}\text { Radius } \\
(\mathrm{cm})\end{array}$} & \multirow[t]{2}{*}{$\csc$} & \multirow[t]{2}{*}{$\begin{array}{l}\lambda e q \\
(W / m \cdot K)\end{array}$} \\
\hline & Lines & Columns & & & \\
\hline 1 & 12 & 1 & 1.63 & 0.97 & 392 \\
\hline 2 & 15 & 1 & 2.06 & 0.96 & 392 \\
\hline 3 & 15 & 1 & 2.52 & 0.95 & 392 \\
\hline 4 & 15 & 1 & 2.91 & 0.94 & 392 \\
\hline 5 & 15 & 1 & 3.26 & 0.93 & 392 \\
\hline 6 & 13 & 1 & 3.83 & 0.92 & 392 \\
\hline 7 & 11 & 1 & 4.50 & 0.91 & 388 \\
\hline 8 & 9 & 1 & 5.32 & 0.89 & 382 \\
\hline 9 & 8 & 1 & 5.98 & 0.88 & 377 \\
\hline 10 & 15 & 2 & 3.26 & 0.87 & 373 \\
\hline 11 & 7 & 1 & 7.07 & 0.86 & 369 \\
\hline 12 & 13 & 2 & 3.83 & 0.85 & 364 \\
\hline 13 & 6 & 1 & 8.30 & 0.83 & 359 \\
\hline 14 & 11 & 2 & 4.50 & 0.82 & 354 \\
\hline 15 & 5 & 1 & 9.77 & 0.80 & 348 \\
\hline 16 & 14 & 3 & 3.48 & 0.79 & 343 \\
\hline 17 & 9 & 2 & 5.48 & 0.78 & 339 \\
\hline 18 & 13 & 3 & 3.83 & 0.77 & 335 \\
\hline 19 & 4 & 1 & 12.30 & 0.75 & 328 \\
\hline 20 & 15 & 4 & 3.26 & 0.74 & 323 \\
\hline 21 & 11 & 3 & 4.50 & 0.73 & 319 \\
\hline 22 & 7 & 2 & 7.07 & 0.72 & 314 \\
\hline 23 & 10 & 3 & 4.94 & 0.70 & 309 \\
\hline 24 & 13 & 4 & 3.83 & 0.69 & 305 \\
\hline 25 & 9 & 3 & 5.43 & 0.67 & 298 \\
\hline
\end{tabular}

\begin{tabular}{|c|c|c|}
\hline 16.61 & 0.67 & 295 \\
\hline 3.50 & 0.65 & 288 \\
\hline 3.57 & 0.64 & 286 \\
\hline 6.20 & 0.63 & 280 \\
\hline 3.83 & 0.62 & 276 \\
\hline 9.93 & 0.60 & 270 \\
\hline 4.12 & 0.59 & 265 \\
\hline 7.07 & 0.58 & 260 \\
\hline 5.48 & 0.56 & 254 \\
\hline 4.50 & 0.55 & 250 \\
\hline 3.83 & 0.54 & 246 \\
\hline 24.27 & 0.51 & 236 \\
\hline 24.59 & 0.51 & 234 \\
\hline 8.30 & 0.50 & 231 \\
\hline 3.26 & 0.48 & 223 \\
\hline 3.30 & 0.47 & 220 \\
\hline 3.83 & 0.46 & 217 \\
\hline 5.52 & 0.45 & 211 \\
\hline 7.07 & 0.43 & 205 \\
\hline 4.13 & 0.42 & 201 \\
\hline 9.88 & 0.41 & 195 \\
\hline 9.99 & 0.40 & 193 \\
\hline 3.83 & 0.39 & 187 \\
\hline 6.24 & 0.38 & 183 \\
\hline 3.55 & 0.36 & 177 \\
\hline 16.45 & 0.34 & 170 \\
\hline 16.61 & 0.34 & 168 \\
\hline 3.80 & 0.32 & 160 \\
\hline 3.83 & 0.31 & 158 \\
\hline 7.07 & 0.29 & 151 \\
\hline 7.14 & 0.29 & 149 \\
\hline 4.54 & 0.27 & 144 \\
\hline 4.13 & 0.26 & 137 \\
\hline 3.80 & 0.24 & 131 \\
\hline 3.83 & 0.23 & 128 \\
\hline 5.55 & 0.22 & 124 \\
\hline 9.93 & 0.21 & 117 \\
\hline 4.50 & 0.19 & 111 \\
\hline 4.54 & 0.18 & 109 \\
\hline 8.30 & 0.17 & 104 \\
\hline 3.83 & 0.16 & 99 \\
\hline 7.13 & 0.14 & 94 \\
\hline 3.33 & 0.13 & 90 \\
\hline 5.52 & 0.12 & 83 \\
\hline 4.98 & 0.10 & 79 \\
\hline 4.53 & 0.09 & 74 \\
\hline 3.83 & 0.08 & 69 \\
\hline 3.33 & 0.07 & 65 \\
\hline 48.53 & 0.03 & 50 \\
\hline 6.98 & 0.02 & 47 \\
\hline 7.03 & 0.02 & 45 \\
\hline 3.30 & 0.01 & 42 \\
\hline 16.61 & 0.00 & 40 \\
\hline
\end{tabular}

